\title{
Russia's HIV rate continues to rise with reactionary policies
}

$\mathrm{H}$ IV infection rates in Russia continue to climb, but the Kremlin persists in rejecting preventive approaches that could help curb the epidemic.

Recent statistics indicate there were about 93000 new cases of HIV in Russia in 2015, with most new infections coming from drug use and heterosexual sex. A million people in Russia have HIV, including almost $1 \%$ of all pregnant women, which is the threshold for a generalized epidemic in the country of 143 million people.

Preventive harm-reduction approaches, such as needle exchanges, methadone replacement therapy and promoting condom use, have reduced rates of HIV infection in other countries, including next door in Ukraine, a country itself in the grip of a longstanding HIV epidemic.

But, for the Kremlin, harm reduction is off the table. A recent report from a Kremlin-backed research institute recommended a "categorical refusal of "harm reduction" programs," arguing that harm reduction is inconsistent with the "Russian model" of fighting HIV.

The report went so far as to blame condom use for Russia's HIV epidemic; one of its coauthors claimed that promoting condom use encourages people to have sex, and argued that the best form of protection against HIV was to "be in a heterosexual family where both partners are loyal to each other."

This kind of approach frustrates Anya Sarang, head of the Moscowbased Andrey Rylkov Foundation, an organization that works with people with drug dependence and those with HIV. She laments how the fight against HIV has become part of the Kremlin's ongoing showdown with the West.

"They see harm reduction as a Western intervention."

For Dr. Vadim Pokrovsky, the head of Russia's federal AIDS centre, the Kremlin's focus on the idea of "risk elimination" instead of harm reduction

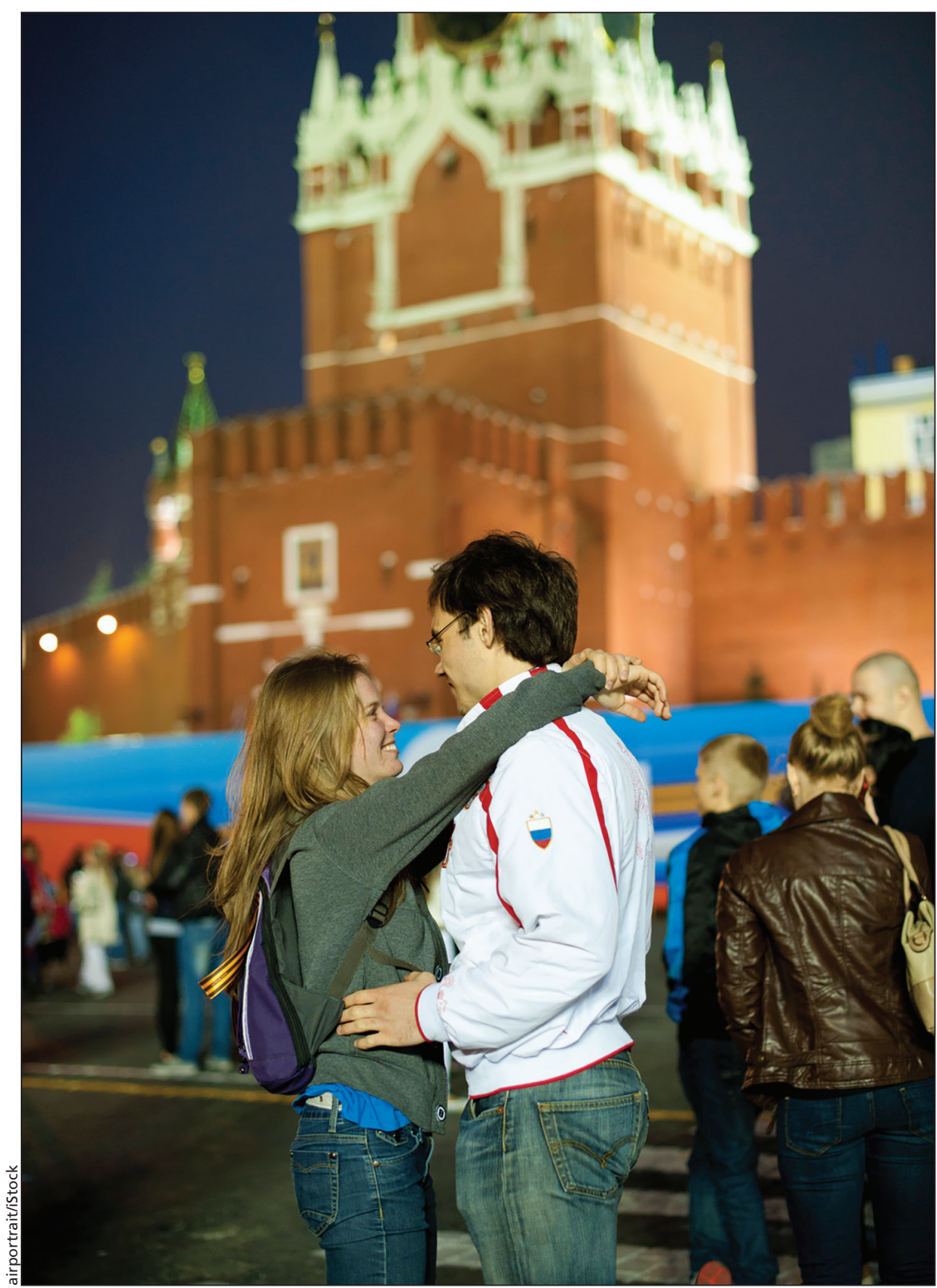

Russia is on the threshold of an HIV epidemic.

is a recipe for failure. "By 'risk elimination' they mean a complete rejection of extramarital sex and drugs. But the experts who understand this know that people just can't give up extramarital sex, and that people dependent on drugs just can't stop using them.'”

Statistics on Russian sexual behaviours back Pokrovsky up. According to a public health survey from 2011,
$61 \%$ of young adults responding to the survey had had sexual intercourse by age 19 .

"The vast majority of young adult first sexual experiences were premarital, regardless of the age when first experience occurred," the report's authors wrote.

But for many observers, the Kremlin's attitude toward methadone replacement 
therapy is the most troubling. Despite clear evidence of its effectiveness, methadone replacement therapy remains illegal in Russia, where distributing the drug even under medical supervision can land one in prison for 20 years.

This policy is now being implemented in Crimea. Immediately after annexing the peninsula from Ukraine in 2014, the Russian government stopped all methadone replacement therapy for those dependent on drugs. Less than a year later, according to the UN's AIDS envoy, 80-100 of the 805 who had been receiving methadone on the peninsula had died by either overdose or suicide.

"I think you could probably point to Russia as a worst-practice for virtually every aspect of how to respond to an HIV epidemic concentrated among drug users," Daniel Wolfe, director of the International Harm Reduction Program at the Open Society Foundations, told The Verge.

The Kremlin's hardening attitudes toward HIV and harm reduction has left activists like Sarang feeling less than hopeful. "I am not optimistic," she says bluntly. - Michael Colborne, Edmonton, Alta.

CMAJ 2016. DOI:10.1503/cmaj.109-5300 